\title{
Composição Corporal de Garrotes Inteiros de Três Grupos Genéticos nas Fases de Recria e Terminação 1
}

\section{Henrique Jorge Fernandes ${ }^{2}$, Mário Fonseca Paulino ${ }^{3}$, Renè Galvão Rezende Martins ${ }^{4}$, Sebastião de Campos Valadares Filho ${ }^{3}$, Robledo de Almeida Torres ${ }^{3}$, Luísa Melville Paiva ${ }^{5}$, Alonso Thiago Silvestre da Silva ${ }^{6}$}

\begin{abstract}
RESUMO - Com os objetivos de avaliar a composição corporal e identificar características corporais mensuráveis capazes de estimar o tamanho relativo de componentes corporais, foram utilizados 36 garrotes inteiros, sendo 12 Nelore, 12 1/2 Holandês x 1/2 Zebu e 12 1/2 Caracu x $1 / 2$ Zebu. Em cada grupo genético, havia seis animais de cada fase de produção: recria e terminação, com peso inicial próximo a $225 \mathrm{~kg}$ e $330 \mathrm{~kg}$, respectivamente. Os animais foram mantidos em regime de confinamento até o abate, realizado de acordo com o peso: 310 a $340 \mathrm{~kg}$ PV para os animais na fase de recria e 420 a $470 \mathrm{~kg}$ PV para aqueles na fase de terminação. Foi fornecida a mesma dieta a todos os animais, com $50 \%$ da matéria seca à base de concentrado e 50\% de silagem pré-seca de coastcross. Utilizou-se um fator geral de 0,8693 para conversão do peso vivo em peso de corpo vazio (obtido a partir dos dados de todos os animais do experimento). Animais provenientes de seleção para corte na categoria terminação apresentaram maiores rendimentos de carcaça (59,2\%) que aqueles de origem leiteira $(56,33 \%)$. Grupos genéticos de raças com aptidão leiteira mostraram tamanhos relativos de órgãos $9 \%$ maior, $21 \%$ menos tecido adiposo na carcaça, bem como maior participação da gordura interna no total de tecido adiposo corporal. Em razão das baixas correlações encontradas, não parece confiável estimar os tamanhos relativos dos componentes corporais estudados a partir das características corporais mensuráveis analisadas.
\end{abstract}

Palavras-chave: carcaça, composição física, cortes comerciais, mestiços, Nelore

\section{Body Composition of Young Bulls of Three Genetic Groups in the Growing and Finishing Phases}

\begin{abstract}
To evaluate the body composition, and to identify measurable body characteristics capable to estimate the relative size of body components, 36 young bulls (12 Nellore, 12 1/2 Holstein x 1/2 Zebu, and 12 1/2 Caracu x $1 / 2$ Cebu) were used. In each genetic group, six animals of each production phase were used: growing animals with initial weight of $225 \mathrm{~kg}$ and the finishing ones with initial weight of $330 \mathrm{~kg}$. The animals were maintained in confinement regime to reach 310 to $340 \mathrm{~kg}$ of weight for the growing animals and 420 to $470 \mathrm{~kg}$ of weight for the finishing ones. The same diet was fed to all the animals, with concentrate level of $50 \%$ in the dry matter and $50 \%$ of coastcross hay. A general factor of .8693 was adopted to conversion of live weight in empty body weight (obtained with the records of all the animals in the experiment). Animals from a beef selection origin, in finishing group, presented higher dressing percentage $(59.2 \%)$ that those of milk selection origin (56.33\%). Genetic groups originating from breeds with milk aptitude showed higher relative sizes of organs (9\% more), $21 \%$ smaller total fatty tissue in carcass, as well as higher participation of internal fatty tissue in total fatty tissue. Despite of the low correlations, it is not reliable to estimate the relative sizes of the body components studied from the analyzed measurable body characteristics.
\end{abstract}

Key Words: carcass, commercial cuts, physical composition, Nellore, crossbred

\section{Introdução}

O objetivo final da produção de bovinos de corte é a produção de carne comercializável. É importante, pois, que se identifiquem genótipos e estratégias de manejo que maximizem a produção de cortes comestíveis de valor mais alto, em detrimento de outras partes do corpo menos valorizadas. A produção animal, no sentido mais empresarial, pode ser medida não como ganho de peso vivo (GPV) ou de peso de corpo vazio (GPCVz), mas sim como o ganho de carne comercializável. Peron et al. (1993a) afirmaram

\footnotetext{
${ }^{1}$ Parte da Dissertação de Mestrado do primeiro autor. Projeto parcialmente financiado pela FAPEMIG.

${ }^{2}$ Professor do curso de Zootecnia da Universidade Estadual de Mato Grosso do Sul - UEMS (henrique@zootecnista.com.br).

3 Professor do Departamento de Zootecnia da Universidade Federal de Viçosa - UFV (mpaulino@ufv.br).

${ }^{4}$ Médico Veterinário, Doutor em Zootecnia pela UFV (renegalvao@yahoo.com).

5 Professora do curso de Zootecnia da Universidade Estadual de Mato Grosso do Sul - UEMS (lumelville@terra.com.br).

${ }^{6}$ Aluno do curso de Agronomia/UFV (alonsoss@terra.com.br).
} 
que, nos rebanhos de corte, se visa obter animais capazes de direcionar grandes quantidades de energia alimentar para produção de carne comercializável.

A carcaça é o principal produto na exploração de bovinos de corte, e a estimativa do rendimento de carcaça e cortes primários é importante para complementar a avaliação do desempenho animal durante seu desenvolvimento (Oliveira, 1999). Os pesos da cabeça (CAB), do couro e do trato gastrointestinal (TGI) também são características importantes, responsáveis pelas variações observadas no rendimento de carcaça entre grupos genéticos (Oliveira, 1999). Os resultados experimentais, de modo geral, têm mostrado maiores rendimentos de carcaça para os grupos genéticos originários de raças de corte, quando comparados àqueles originários de raças leiteiras ou seus mestiços (Peron et al., 1993a; Castillo Estrada,1996; Galvão et al., 1991).

No Brasil, a carcaça é dividida em dianteiro com cinco costelas (que envolve o acém-AC e a paleta$\mathrm{PAL}$, completos), ponta de agulha-PO e traseiro especial (que envolve o coxão-COX e a alcatra-ALC completos). Economicamente, deseja-se maior rendimento do traseiro, pois é onde se encontram os cortes mais valorizados pelo mercado.

Véras et al. (2001b) compararam os animais caracterizados como de maturidade tardia e os de maturidade precoce. Segundo os autores, animais precoces tendem a apresentar maiores conteúdos corporais de gordura e menores de proteína, quando submetidos a uma mesma dieta, o que estaria ligado à genética dos mesmos.

Ferrel \& Jenkins (1998a,b) associaram a eficiência de uso da energia metabolizável para ganho com o peso e a atividade metabólica de órgãos e vísceras (sobretudo intestinos e fígado).

Garret (1980), citado por Signoretti et al. (1999a), afirmou que a raça teve mais influência sobre a composição corporal que o nível nutricional. De modo geral, o nível de ingestão de energia pode modificar a partição de energia para depósito de proteína ou gordura, em termos do desenvolvimento de tecidos muscular e adiposo. Signoretti et al. (1999a) afirmaram ainda que o ponto crucial é que se identifique a extensão da possível manipulação destes componentes por via nutricional ou genética. Parece que, em animais de maturidade tardia, a redução do nível de energia resulta em efeito mais depressivo sobre a retenção de proteína (tecido muscular) que sobre a deposição de gordura, ao contrário do que ocorreria em animais de maturidade precoce.
Peron et al. (1993b) destacaram a importância dos depósitos cavitários e viscerais de tecido adiposo (ADvis), afirmando que a distribuição do tecido adiposo no corpo animal é função da raça e do estado fisiológico e nutricional do animal. Diferenças entre os locais de depósito adiposo em vários grupos genéticos foram relatadas por vários autores (Peron et al., 1993b; Véras et al., 2001a; Owens et al., 1995; Signoretti et al., 1999b). Apesar de resultados diversos, parece haver um padrão em que animais oriundos de raças de corte tendem a apresentar maior deposição periférica de tecido adiposo, enquanto animais provenientes de seleção leiteira buscam depositar gordura interna. Oliveira (1999) também relatou que diversos autores têm encontrado maiores pesos de órgãos em bovinos de origem leiteira. Estes maiores tamanhos de órgãos (ORG) têm sido associados a maiores exigências nutricionais de mantença destes animais.

Buscando estimativas menos subjetivas dos componentes corporais, diversas medidas do corpo animal têm sido testadas quanto às suas correlações com características importantes da carcaça, ou dos componentes corporais não-integrantes desta.

Segundo Guimarães (1999), resultados experimentais têm mostrado que o peso e o comprimento da carcaça, a espessura de gordura sobre a $12^{\mathrm{a}}$ costela e a área transversal do músculo Longissimus dorsi são parâmetros úteis, quando se deseja estimar a quantidade fisicamente separável de gordura e músculos na carcaça. Os mesmos autores, no entanto, apresentaram indícios de que estes parâmetros proporcionam estimativas com precisão pouco superior àquelas obtidas em função apenas do peso de corpo vazio (PCVz).

Guimarães (1999), em revisão sobre o ganho compensatório, observa que a composição e a própria proporção do peso vivo recuperado irão depender da idade à época da restrição, da duração do período de recuperação, da taxa de ganho e da qualidade do alimento durante a recuperação. Esse autor afirma ainda que a recuperação de peso de cada componente da carcaça no período de recuperação tende a restaurar a composição de animais em alimentação contínua. Caso haja tempo no período de recuperação, parece que este objetivo pode ser alcançado. Berg \& Butterfield (1976) afirmaram que, quando não há tempo ou condições de o animal recuperar sua composição corporal original durante o período de re-alimentação, normalmente observa-se maior

\section{R. Bras. Zootec., v.33, n.6, p.1581-1590, 2004}


conteúdo de tecido muscular nos animais submetidos à restrição e re-alimentação que naqueles com crescimento ininterrupto.

Este trabalho foi realizado com os objetivos de avaliar a composição corporal e identificar características corporais mensuráveis capazes de estimar o tamanho relativo de componentes corporais, utilizando-se bovinos de três grupos genéticos abatidos com peso vivo entre 310 e $340 \mathrm{~kg}$ e 420 e $470 \mathrm{~kg}$ para as categorias recria e terminação, respectivamente.

\section{Material e Métodos}

O presente trabalho foi desenvolvido no laboratório de animais do Departamento de Zootecnia da Universidade Federal de Viçosa.

Foram utilizados 36 garrotes inteiros, sendo 12 Nelores, 12 1/2 Holandês x 1/2 Zebu e 12 1/2 Caracu x 1/2 Zebu. Estes animais foram divididos em dois grupos, de acordo com o peso vivo (PV) inicial médio. Animais com peso médio inicial próximo a $225 \mathrm{~kg}$ foram definidos como representantes da recria e aqueles com peso inicial próximo a $330 \mathrm{~kg}$, como pertencentes à categoria terminação. Em cada categoria, foram alocados seis animais de cada grupo genético.

Os animais foram distribuídos em baias individuais com piso concretado e área de $30 \mathrm{~m}^{2}$, sendo $8 \mathrm{~m}^{2}$ cobertos com telhas de amianto e $22 \mathrm{~m}^{2}$ de área descoberta. Todas as baias eram providas de bebedouro e comedouro de cimento.

Antes de se iniciar o experimento, os animais foram submetidos a controle de endo e ectoparasitas, identificados com brinco e receberam 2.000.000 de unidades internacionais de vitamina A.

Foi fornecida uma mesma dieta para todos os animais. Nesta dieta, 50\% da matéria seca foi uma mistura concentrada à base de farelo de trigo, farelo de soja e milho, devidamente suplementado com minerais. O volumoso, responsável pelos outros $50 \%$ da matéria seca da ração, era silagem présecada de coastcross, adquirida de produtores comerciais. A dieta total foi balanceada, segundo as tabelas de exigência do NRC (1996), para ganho de peso vivo diário de $1,2 \mathrm{~kg}$; utilizando o "Sistema Viçosa de formulação de rações" (Lana, 2000) para ajuste da mesma. Os animais receberam, durante todo o período experimental, esta dieta balanceada ad libitum. A ração foi fornecida uma vez ao dia no início da manhã, completando-se os cochos vazios no período da tarde.
Após um período de adaptação de sete dias, dois animais de cada grupo genético dentro de cada categoria foram designados para o abate, servindo de referência no estudo da composição corporal. Os animais restantes foram mantidos em regime de confinamento até o abate, realizado de acordo com o seguinte critério: 310 a $340 \mathrm{~kg}$ de peso vivo, para os animais do grupo recria, e 420 a $470 \mathrm{~kg}$ de peso vivo, para os animais do grupo terminação.

Os animais foram pesados a cada 28 dias. À medida que um animal se aproximava do peso de abate pré-estabelecido, era definida a data de abate a partir de uma projeção da evolução do peso vivo do animal, com base no ganho de peso médio diário do último período. Antes do abate, os animais foram submetidos a jejum de 16 horas.

De cada animal abatido foram pesados o rúmen, retículo, omaso, abomaso, intestinos delgado e grosso cheios e vazios, sangue, mesentério, carne industrial, gordura interna, fígado, coração, rins, baço, pulmões, língua, couro, cauda, esôfago, traquéia, aparelho reprodutor, cabeça e pés.

As duas meia-carcaças foram pesadas no dia do abate e, posteriormente, resfriadas em câmara fria $\left(-5^{\circ} \mathrm{C}\right)$, durante, aproximadamente, 22 horas. Após esse período, foram retiradas da câmara fria, novamente pesadas (para obtenção do peso de carcaça resfriada), coletando-se uma amostra representativa da meia-carcaça esquerda (seção HH), correspondente à seção da 9a a 11 $\underline{a}$ costela, segundo Hankins \& Howe (1946), para posterior dissecação e avaliação dos componentes físicos da carcaça. Nesta oportunidade, também foram medidos o comprimento da meiacarcaça direita - COMPCAR, a área da seção transversal do músculo Longissimus dorsi (área de olho de lombo - AOL) e a espessura de gordura subcutânea na posição da $12^{\mathrm{a}}$ costela (EGOR) na meia-carcaça esquerda, segundo metodologia descrita por Galvão et al. (1991), e o peso dos cortes básicos da carcaça - PAL, AC, PO, ALC e COX - na meia-carcaça direita, de acordo com metodologia descrita por Peron et al. (1993a).

Para o estudo do rendimento dos cortes básicos, utilizou-se a meia-carcaça direita, separando-se o dianteiro do traseiro, entre quinta e sexta costelas. $\mathrm{O}$ dianteiro foi dividido em AC e PAL completos; e o traseiro, em PO, COX e ALC.

A partir das proporções de músculo, tecido adiposo e ossos observados na seção $\mathrm{HH}$, determinou-se a proporção dos mesmos na carcaça, segundo as equações desenvolvidas por Hankins \& Howe (1946).

\section{R. Bras. Zootec., v.33, n.6, p.1581-1590, 2004}



Músculo:
$\mathrm{Y}=16,08+0,80 \mathrm{X}$
Tecido adiposo:
$\mathrm{Y}=3,54+0,80 \mathrm{X}$
Ossos:
$\mathrm{Y}=5,52+0,57 \mathrm{X}$

em que $\mathrm{X}$ é a porcentagem dos componentes na seção $\mathrm{HH}$.

O total de tecidos adiposos no corpo (TADC) foi determinado pela soma do peso de tecido adiposo da carcaça (ADcar), de mesentério e de gordura interna; o total de ADvis, pela soma dos pesos de mesentério e de gordura interna; o total de ORG, pela soma dos pesos de carne industrial, fígado, coração, rins, baço, pulmões e língua; e o total de vísceras (VIS), pela soma dos pesos de rúmen, retículo, omaso, abomaso, intestino delgado, intestino grosso, mesentério, gordura interna, esôfago, traquéia e aparelho reprodutor.

O PCVZ dos animais foi determinado pela soma do peso de carcaça, sangue, cabeça, couro, cauda, pés, vísceras e órgãos, de acordo com a metodologia descrita por Paulino et al. (1999). Estimou-se a relação entre o PCVZ e o PV de cada animal, e calculou-se um fator de conversão médio, utilizando-se os dados de todos os animais do experimento em conjunto.

$O$ rendimento de carcaça foi calculado como a divisão do peso de carcaça quente pelo PCVZ e pelo PV do animal ao abate.

Avaliou-se o peso relativo de ORG, VIS, TGI, partes do corpo (couro, pés, cabeça e rabo), cortes comerciais da carcaça (PAL, AC, PO, ALC e COX), além dos tecidos constituintes da carcaça (músculo da carcaça MC, tecido adiposo da carcaça - ADcar, ossos da carcaça - OC), do ADvis e TADC, em relação ao PV de abate dos animais. Avaliou-se, ainda, o peso relativo do ADvis, em relação ao TADC do animal (ADvis/tot).

Por serem grupos de animais diferentes, manejados de forma independente, os dados de cada categoria foram analisados separadamente. Dentro de cada categoria, as características foram analisadas a partir de um modelo que considerou o efeito de grupo genético e utilizou o peso de corpo vazio como covariável, conforme o modelo:

$$
y_{i j}=\mu+G_{i}+b\left(P_{i j}-\bar{P}\right)+e_{i j}
$$

em que $\mu=$ efeito da média; $y_{i j}=$ observação referente ao animal $j$ do grupo genético $i ; \mathrm{G}_{\mathrm{i}}=$ efeito do grupo genético $i ; b=$ coeficiente de regressão linear da característica em função da co-variável; $\mathrm{P}_{\mathrm{ij}}=$ peso de corpo vazio ao abate do animal $\mathrm{j}$, do grupo genético $\mathrm{i} ; \mathrm{P}=$ peso médio de corpo vazio ao abate; e $\mathrm{e}_{\mathrm{ij}}=$ erro aleatório.

\footnotetext{
R. Bras. Zootec., v.33, n.6, p.1581-1590, 2004
}

Utilizou-se o procedimento GLM (proc GLM) do SAS (SAS, 1989) para a realização das análises de variância e dos testes de comparação de médias. Quando identificado um efeito significativo, comparavam-se as médias de cada grupo genético, dentro de cada categoria, pelo teste Tukey. Adotou-se o nível de 5\% de significância para todas as análises realizadas.

Avaliaram-se também as correlações entre cada característica corporal estudada, o peso corporal vazio e as características mensuráveis da carcaça (EGOR, COMPCAR e AOL). As correlações foram estimadas para cada grupo genético, para cada categoria e para todos os dados em conjunto, de forma a identificar as variações. Utilizou-se o procedimento "Regression" (proc REG) do SAS (SAS, 1989) para estimativa e análise dos coeficientes de correlação.

\section{Resultados e Discussão}

Utilizando-se os dados de todos os animais do experimento em conjunto, estimou-se um fator de conversão geral de 0,8693 entre o PV e o PCVZ. Pela simplicidade de implementação do mesmo e pela similaridade com o fator preconizado pelo NRC em 1996 (PCVZ = PV x 0,891), adotou-se este fator de conversão para transformação do PV em PCVZ.

$\mathrm{Na}$ Tabela 1, encontram-se os PV e PCVZ iniciais e finais de cada grupo genético em cada categoria.

$\mathrm{Na}$ Tabela 2, encontram-se as médias de rendimento de carcaça para os três grupos genéticos nas duas categorias. A análise de variância do rendimento de carcaça mostrou efeito $(\mathrm{P}<0,01)$ de grupo genético apenas na categoria terminação. Os animais Nelore apresentaram rendimentos superiores aos grupos genéticos cruzados (que não diferiram entre si). Estes resultados comprovam a tendência de que animais de origem leiteira apresentam menores rendimentos de carcaça. Também na categoria recria, observa-se este mesmo comportamento. Galvão et al. (1991), trabalhando com mestiços de europeus $\mathrm{x}$ Nelore com origem de raças de corte, encontraram melhores rendimentos de carcaça para os animais cruzados. Os mesmos autores, no entanto, citam diversos trabalhos para mostrar resultados comprovando que o cruzamento da raça Nelore com raças taurinas leiteiras tende a reduzir o rendimento de carcaça dos animais. Castillo Estrada (1996) e Peron et al. (1993a), trabalhando com diversos mestiços, confirmaram esta tendência, uma vez que os mesti- 
Tabela 1 -Médias e desvios-padrão dos pesos vivo inicial (PVi) e final (PVf), e dos pesos de corpo vazio inicial (PCVZi) e final (PCVZf) de três grupos genéticos, nas fases de recria e terminação

Table 1 - Means and standard deviations of initial (ILW) and final (FLW) live weight, and initial (IEBW) and final (FEBW) empty body weight, of three genetic groups, in the growing and finishing phases

\begin{tabular}{|c|c|c|c|c|c|c|}
\hline \multirow[b]{2}{*}{$\begin{array}{l}\text { Grupo genético } \\
\text { Genetic group }\end{array}$} & \multicolumn{3}{|c|}{ Recria (Growing) } & \multicolumn{3}{|c|}{ Terminação (Finishing) } \\
\hline & $1 / 2 \operatorname{Car}^{1}$ & $1 / 2 \mathrm{Hol}^{2}$ & $\mathrm{Nel}^{3}$ & $1 / 2 \mathrm{Car}$ & $1 / 2 \mathrm{Hol}$ & Nel \\
\hline $\operatorname{PVi}(\mathrm{kg})(I L W)$ & $266,8 \pm 28,6$ & $200,7 \pm 31,3$ & $210,2 \pm 8,8$ & $349,5 \pm 28,4$ & $350,3 \pm 14,5$ & $295,8 \pm 50,0$ \\
\hline $\operatorname{PVf}(\mathrm{kg})(F L W)$ & $341,7 \pm 23,2$ & $315,7 \pm 5,7$ & $317,3 \pm 5,0$ & $468,7 \pm 13,5$ & $469,7 \pm 7,0$ & $422,2 \pm 48,2$ \\
\hline $\operatorname{PCVZi}(\mathrm{kg})(I E B W)$ & $240,2 \pm 15,3$ & $187,0 \pm 14,0$ & $186,99 \pm 11,2$ & $303,7 \pm 26,8$ & $296,5 \pm 26,3$ & $259,5 \pm 44,6$ \\
\hline $\operatorname{PVZf}(\mathrm{kg})(F E B W)$ & $299,4 \pm 20,8$ & $275,1 \pm 4,9$ & $279,91 \pm 6,5$ & $412,0 \pm 12,0$ & $411,0 \pm 8,6$ & $377,8 \pm 40,7$ \\
\hline
\end{tabular}

$11 / 2$ Caracu x $1 / 2$ Zebu (1/2 Caracu x $1 / 2$ Zebu).

$21 / 2$ Holandês $\times 1 / 2$ Zebu (1/2 Holstein $\times 1 / 2$ Zebu).

3 Nelore (Nellore).

Tabela 2 - Médias e desvios-padrão do rendimento de carcaça em relação ao peso de corpo vazio (RENDvz) e ao peso vivo (RENDv) em três grupos genéticos, nas fases de recria e terminação

Table 2 - Means and standard deviations of carcass yield in relation to the empty body weight (RELew) and to the live weight (RELIw) for three genetic groups in the growing and finishing phases

\begin{tabular}{|c|c|c|}
\hline Grupo genético & RENDvz $(\%)$ & RENDv $(\%)$ \\
\hline \multirow[t]{2}{*}{ Genetic group } & RELew (\%) & RELlw (\%) \\
\hline & \multicolumn{2}{|c|}{ Recria } \\
\hline $1 / 2 \mathrm{Car}^{1}$ & $62,19 \pm 0,42$ & $54,50 \pm 1,63$ \\
\hline $1 / 2 \mathrm{Hol}^{2}$ & $61,73 \pm 1,11$ & $53,80 \pm 1,09$ \\
\hline \multirow[t]{2}{*}{$\mathrm{Nel}^{3}$} & $63,07 \pm 1,09$ & $55,62 \pm 0,45$ \\
\hline & \multicolumn{2}{|c|}{ Terminação } \\
\hline $1 / 2$ Car & $64,08^{a} \pm 0,81$ & $56,33^{a} \pm 0,93$ \\
\hline $1 / 2 \mathrm{Hol}$ & $64,39^{\mathrm{a}} \pm 0,53$ & $56,33^{\mathrm{a}} \pm 0,39$ \\
\hline Nel & $66,17^{b} \pm 0,84$ & $59,23^{\mathrm{b}} \pm 0,85$ \\
\hline
\end{tabular}

Médias da mesma coluna, dentro da mesma categoria, seguidas pela mesma letra não diferem pelo teste de Tukey a $5 \%$.

Means, in a collumn, within the same category, followed by the same letter, do no differ by Tukey test at $5 \%$.

$11 / 2$ Caracu $\times 1 / 2$ Zebu (1/2 Caracu $\times 1 / 2$ Zebu).

$21 / 2$ Holandês $\times 1 / 2$ Zebu (1/2 Holstein $\times 1 / 2$ Zebu).

${ }^{3}$ Nelore (Nellore).

ços leiteiros apresentaram menores rendimentos e os mestiços de corte tenderam a apresentar maiores rendimentos que os animais Nelore desses experimentos.

$\mathrm{Na}$ avaliação do tamanho relativo dos componentes corporais na categoria recria, observou-se efeito significativo $(\mathrm{P}<0,05)$ de grupo genético para os percentuais de TGI, VIS, pés, ADcar e ADvis/tot, ao passo que, na categoria terminação, o grupo genético influenciou $(\mathrm{P}<0,05)$ apenas o percentual de OR e CAB. Constam, na Tabela 3, as médias do tamanho relativo de cada componente corporal no PV do animal.

Observou-se tendência de os grupos genéticos com participação de raças de maior aptidão leiteira apresentarem maiores ORG e VIS. Na maioria das características ligadas ao tamanho de órgãos e vísceras, observou-se uma escala crescente no tamanho relativo desses componentes corporais, em que os animais Nelore (originários de seleção tipicamente de corte) apresentaram os menores tamanhos relativos, seguidos dos animais 1/2 Caracu x $1 / 2$ Zebu (de origem em uma raça de dupla aptidão) e, finalmente, dos animais $1 / 2$ Holandês $x 1 / 2$ Zebu com os maiores tamanhos relativos. Este comportamento é coerente com os efeitos observados em animais submetidos à seleção leiteira, que tende a privilegiar animais com maior desenvolvimento de ORG e VIS, graças à maior capacidade de ingestão de alimentos e maior atividade metabólica dos mesmos. Freitas (1995) atribuiu a este maior tamanho de ORG dos animais com origem leiteira, maiores exigências nutricionais de mantença destes animais. Por outro lado, as raças zebuínas de corte (incluindo a raça Nelore) se adaptam a condições ambientais adversas (em especial à exposição a períodos de baixa disponibilidade de alimentos). Esta situação beneficia animais de baixa exigência de mantença - sobretudo aqueles de baixo metabolismo basal, com ORG e VIS proporcionalmente menores, e menos ativos. Peron et al. (1993b) e Jorge et al. (1999a) também destacam a tendência de animais mestiços de raças leiteiras apresentarem massa de órgãos internos proporcionalmente maior que animais

\section{R. Bras. Zootec., v.33, n.6, p.1581-1590, 2004}


Tabela 3 -Tamanho relativo (\% PV) médio de partes do corpo, cortes básicos da carcaça, tecidos constituintes da carcaça e tecidos adiposos de três grupos genéticos, nas fases de recria e terminação

Table 3 - Average relative weight (\%LW) of body cuts, carcass prime cuts, carcass tissues, and fat tissues of three genetic groups, in the growing and finishing phases

\begin{tabular}{|c|c|c|c|c|c|c|}
\hline \multirow[b]{2}{*}{$\begin{array}{l}\text { Grupo genético } \\
\text { Genetic group }\end{array}$} & \multicolumn{3}{|c|}{ Recria (Growing) } & \multicolumn{3}{|c|}{ Terminação (Finishing) } \\
\hline & $1 / 2 \operatorname{Car}^{1}$ & $1 / 2 \mathrm{Hol}^{2}$ & $\mathrm{Nel}^{3}$ & $1 / 2 \mathrm{Car}$ & $1 / 2 \mathrm{Hol}$ & $\mathrm{Nel}$ \\
\hline & \multicolumn{5}{|c|}{ Partes do corpo (Body cuts) } & \\
\hline Órgãos (Organs) & 3,82 & 4,01 & 3,47 & $3,29^{\mathrm{a}}$ & $3,72^{b}$ & $3,19^{\mathrm{a}}$ \\
\hline $\mathrm{TGI}^{4}$ & $4,70^{\mathrm{a}}$ & $4,79^{\mathrm{a}}$ & $3,96^{\mathrm{b}}$ & 4,18 & 4,24 & 3,93 \\
\hline Vísceras (Viscera) & $9,84^{\mathrm{a}}$ & $9,63^{\mathrm{a}}$ & $8,57^{b}$ & 9,77 & 9,42 & 9,62 \\
\hline Couro (Leather) & 9,46 & 8,97 & 10,36 & 8,78 & 8,26 & 8,93 \\
\hline Pés (Foot) & $1,84^{\mathrm{a}}$ & $2,65^{\mathrm{b}}$ & $2,66^{\mathrm{b}}$ & 2,11 & 2,12 & 2,01 \\
\hline Cabeça (Head) & 4,06 & 3,67 & 3,82 & $3,74^{\mathrm{a}}$ & $3,39^{b}$ & $3,31^{b}$ \\
\hline \multirow[t]{2}{*}{ Rabo (Tail) } & 0,25 & 0,25 & 0,26 & 0,25 & 0,25 & 0,29 \\
\hline & \multicolumn{6}{|c|}{ Cortes básicos da carcaça (Carcass prime cuts) } \\
\hline Paleta (Shoulder) & 10,00 & 9,38 & 9,48 & 9,3 & 9,62 & 9,72 \\
\hline Acém ("Acém") & 13,16 & 11,12 & 12,04 & 13,52 & 13,34 & 13,9 \\
\hline Ponta agulha (Spare ribs) & 8,38 & 5,88 & 6,18 & 7,46 & 7,34 & 7,70 \\
\hline Alcatra (Whole sholder) & 10,52 & 9,26 & 10,26 & 10,2 & 10,14 & 10,72 \\
\hline \multirow[t]{2}{*}{ Coxão(Cushion) } & 15,16 & 15,42 & 16,22 & 14,82 & 15,58 & 15,86 \\
\hline & \multicolumn{5}{|c|}{ Tecidos da carcaça (Carcass tissues) } & \\
\hline $\mathrm{MC}^{5}$ & 37,34 & 35,65 & 36,62 & 36,78 & 37,76 & 37,75 \\
\hline $\mathrm{OC}^{6}$ & 8,06 & 9,25 & 8,52 & 8,94 & 8,90 & 9,04 \\
\hline \multirow[t]{2}{*}{ ADcar $^{7}$} & $9,41^{\mathrm{a}}$ & $8,74^{\mathrm{a}}$ & $10,77^{\mathrm{b}}$ & 10,58 & 9,76 & 12,67 \\
\hline & \multicolumn{5}{|c|}{ Tecidos adiposos (Fat tissues) } & \\
\hline ADvis 8 & 3,39 & 3,11 & 2,94 & 3,95 & 3,52 & 3,80 \\
\hline ADvis/tot ${ }^{9}$ & $26,58^{\mathrm{a}}$ & $26,40^{\mathrm{a}}$ & $21,53^{\mathrm{b}}$ & 27,21 & 26,75 & 23,09 \\
\hline $\mathrm{TADC}^{10}$ & 12,81 & 11,85 & 13,72 & 14,54 & 13,28 & 16,48 \\
\hline
\end{tabular}

Médias na mesma linha, dentro da mesma categoria, seguidas pela mesma letra, não diferem pelo teste de Tukey a $5 \%$.

Means, in a line, within the same category, followed by the same letter, do no differ by Tukey test at $5 \%$.

$1 \frac{1}{2}$ Caracu $x 1 / 2$ Zebu ( $1 / 2$ Caracu $\times 1 / 2$ Zebu).

$21 / 2$ Holandês $\times 1 / 2$ Zebu ( $1 / 2$ Holstein $\times 1 / 2$ Zebu).

3 Nelore (Nellore).

4 Trato gastrointestinal (Gastrointestinal tract).

5 Tecido muscular da carcaça (Carcass muscle tissue).

6 Tecido ósseo da carcaça (Carcass bone tissue).

7 Tecido adiposo da carcaça (Carcass fat tissue).

8 Tecido adiposo visceral (Visceral fat tissue).

9 Percentual do tecido adiposo visceral sobre o total de tecido adiposo corporal (Visceral fat tissue on the total of body fat tissue) = ADvis/TADCV.

10 Total de tecido adiposo corporal (Total of body fat tissue).

tipicamente de corte.

Assim como neste experimento, Peron et al. (1993a), Jorge et al. (1997b) e Jorge et al. (1999b), também não encontraram efeito de grupo genético quanto ao tamanho relativo dos cortes comerciais. Zervoudakis et al. (2001) atribuem esta ausência de diferenças à tendência de os animais, independentemente de grupos genéticos, buscarem o equilíbrio entre os quartos dianteiro e traseiro.

Castillo Estrada (1996) e Jorge et al. (1999b) também não encontraram diferenças significativas entre grupos genéticos no que se refere à proporção dos tecidos constituintes da carcaça. Esses autores, bem como Jorge et al. (1997a) e Galvão et al. (1991), observaram tendência de os animais Nelore apresentarem maiores teores de ADcar e menores teores de OC e MC que mestiços, ao final do período de terminação, o que seria indicativo da maior precocidade de terminação dos animais Nelore. No presente trabalho, entretanto, não se verificou a tendência deste grupo genético apresentar menores teores de MC. O teor mais elevado de MC no grupo genético Nelore, discrepante da literatura, pode ser atribuído a um ganho compensatório incompleto realizado pelos animais Nelore, durante o experimento.

Neste experimento, o percentual observado de MC foi maior e o de ADcar, menor que os relatados por Castillo Estrada (1996), Oliveira (1998) e Gesualdi 
Tabela 4 - Médias e desvios-padrão de comprimento de carcaça (COMPCAR), espessura de gordura (EGOR) e área de olho de lombo (AOL) na $12^{\mathrm{a}}$ costela, em três grupos genéticos, nas fases de recria e terminação

Table 4 - Means and standard deviations of carcass length (LENCAR), fat thickness (FAT), and loin eye area (LEA) in the $12^{\text {th }}$ rib, in three genetic groups, in the growing and finishing phases

\begin{tabular}{|c|c|c|c|c|c|c|}
\hline \multirow[b]{2}{*}{$\begin{array}{l}\text { Grupo genético } \\
\text { Genetic group }\end{array}$} & \multicolumn{3}{|c|}{ Recria (Growing) } & \multicolumn{3}{|c|}{ Terminação (Finishing) } \\
\hline & $1 / 2$ Car $^{1}$ & $1 / 2 \mathrm{Hol}^{2}$ & $\mathrm{Nel}^{3}$ & $1 / 2 \mathrm{Car}$ & $1 / 2 \mathrm{Hol}$ & $\mathrm{Nel}$ \\
\hline $\operatorname{COMPCAR}(\mathrm{m})($ LENCAR $)$ & $1,08 \pm 0,05$ & $1,09 \pm 0,058$ & $1,09 \pm 0,051$ & $1,18 \pm 0,02$ & $1,21 \pm 0,01$ & $1,14 \pm 0,039$ \\
\hline $\operatorname{EGOR}(\mathrm{mm})(F A T)$ & $1,45 \pm 0,14$ & $0,83 \pm 0,104$ & $1,26 \pm 0,52$ & $2,40 \pm 0,93$ & $1,38 \pm 0,55$ & $2,03 \pm 0,21$ \\
\hline $\operatorname{AOL}\left(\mathrm{cm}^{2}\right)(L E A)$ & $69,49 \pm 6,14$ & $55,03 \pm 5,64$ & $53,25 \pm 2,19$ & $73,90 \pm 6,01$ & $80,23 \pm 6,19$ & $69,99 \pm 10,43$ \\
\hline
\end{tabular}

$11 / 2$ Caracu $\times 1 / 2$ Zebu (1/2 Caracu $\times 1 / 2$ Zebu).

$21 / 2$ Holandês $\times 1 / 2$ Zebu (1/2 Holstein $\times 1 / 2$ Zebu).

${ }^{3}$ Nelore (Nellore).

Jr. et al. (2000). Estes resultados indicam que o abate dos animais nestes trabalhos foi realizado em um estádio de maturidade mais avançado.

O TADC mostrou tendência de ser maior, quanto maior a aptidão de corte da raça de origem. Observa-se, no entanto, que esta tendência está mais ligada à deposição de ADcar, pois o percentual de ADvis é semelhante para todos os grupos genéticos. Como conseqüência, em relação ao TADC, os animais de origem leiteira tenderam a depositar maior percentual na forma de ADvis, enquanto o grupo genético Nelore priorizou depósito de ADcar. Esta maior deposição de tecido adiposo na carcaça de animais Nelore pode ainda ser indicativo de maior precocidade de terminação de carcaça destes animais, o que estaria ligado ao menor peso adulto dos animais (conseqüência do processo seletivo natural de adaptação a condições de deficiência nutricional). A deposição preferencial de ADvis dos animais de origem leiteira também é coerente com o processo seletivo para produção de leite, que, privilegiando animais metabolicamente mais ativos, necessita mais de ADvis (como reserva energética de mobilização mais rápida para os órgãos que o tecido adiposo da carcaça). Peron et al. (1993b) também observaram que animais com aptidão leiteira tenderam a depositar maior proporção do tecido adiposo corporal nas vísceras, ao contrário de raças de corte.

A análise de variância não indicou efeito significativo de grupo genético, em nenhuma das categorias, para os parâmetros mensuráveis da carcaça (Tabela 4). A alta variabilidade observada nos dados de EGOR pode explicar a falta de significância das diferenças observadas para esta variável. Verifica-se, neste caso, tendência de o grupo genético $1 / 2$ Holandês x $1 / 2$ Zebu (de maior aptidão leiteira) apresentar uma carcaça com menor coberta de gordura em relação aos outros grupos genéticos (que já sofreram alguma seleção para produção de carne). $O$ COMPCAR e a AOL dos animais dos três grupos genéticos, nas fases de recria e terminação, foram semelhantes.

Constam da Tabela 5 os coeficientes de correlação entre características mensuráveis do animal e seus componentes corporais. Entre os cortes comerciais da carcaça, o tamanho relativo de ALC parece não se correlacionar com nenhuma das características corporais avaliadas, ao passo que o tamanho relativo do AC apresentou altas e significativas correlações com o PCVZ, o COMPCAR, a EGOR e a AOL. Estas correlações positivas identificadas mostram que o tamanho relativo deste corte tende a ser maior, à medida que o animal cresce. Apesar de a PAL apresentar correlações significativas com várias características mensuráveis, estas possuem valores apenas medianos. De modo geral, parece haver tendência de o tamanho relativo da PAL reduzir-se com o crescimento do animal, graças às correlações negativas com PCVZ, COMPCAR e AOL. Verifica-se efeito de grupo genético nas correlações da PO com as características mensuráveis do animal, comprovado pelas boas correlações obtidas dentro dos grupos genéticos $1 / 2$ Holandês $x 1 / 2$ Zebu e Nelore, o que não se confirma quando se avaliam os dados dos animais $1 / 2$ Caracu $x 1 / 2$ Zebu ou do grupo total de animais (geral). Também os dados deste corte na categoria recria apresentam alta e positiva correlação com o PCVZ e a AOL. Com base nestes resultados, pode-se inferir que, na fase de vida correspondente à recria, há crescimento do tamanho relativo da PO mais que proporcional ao crescimento do animal. Esta tendência não apresenta continuidade na fase de terminação, justificando as correlações controversas obser- 
Tabela 5 - Coeficientes de correlação entre tamanho relativo de cortes básicos da carcaça, tecidos da carcaça e tecidos adiposos e características mensuráveis do corpo em três grupos genéticos, nas fases de recria e terminação e, para todos os dados analisados em conjunto (geral)

Table 5 - Correlation coefficients between the relative size of carcass basic cuts, carcass tissues, and fatty tissues, and measured traits of body in three genetic groups, in the growing and finishing phases and analyzed in overall

\begin{tabular}{|c|c|c|c|c|c|c|c|}
\hline $\begin{array}{l}\text { Característica } \\
\text { corporal } \\
\text { Body trait } \\
\end{array}$ & $\begin{array}{l}\text { Característica } \\
\text { mensurável } \\
\text { Measured trait } \\
\end{array}$ & $1 / 2 \mathrm{Car}^{1}$ & $1 / 2 \mathrm{Hol}^{2}$ & $\mathrm{Nel}^{3}$ & $\begin{array}{c}\text { Recria } \\
\text { Growing }\end{array}$ & $\begin{array}{c}\text { Terminação } \\
\text { Finishing }\end{array}$ & $\begin{array}{c}\text { Geral } \\
\text { Overall }\end{array}$ \\
\hline $\begin{array}{l}\text { Paleta } \\
\text { (\%PCVZ) } \\
\text { Sholder } \\
(\% E B W)\end{array}$ & $\begin{array}{l}\text { PCVZ }(\mathrm{kg})^{4} \\
\text { COMPCAR }(\mathrm{cm})^{5} \\
\text { EGOR }(\mathrm{mm})^{6} \\
\text { AOL }\left(\mathrm{cm}^{2}\right)^{7}\end{array}$ & $\begin{array}{l}-0,3945 \\
-0,4992 \\
-0,0418 \\
-0,0873\end{array}$ & $\begin{array}{r}-0,5242 \\
-0,4975 \\
0,0717 \\
-0,4230\end{array}$ & $\begin{array}{r}-0,5541 \\
-0,3097 \\
0,1061 \\
-0,5416\end{array}$ & $\begin{array}{l}0,2282 \\
0,0049 \\
0,4534 \\
0,4236\end{array}$ & $\begin{array}{r}0,1395 \\
0,2563 \\
0,2075 \\
-0,0637\end{array}$ & $\begin{array}{c}-0,5036^{* *} \\
-0,4096^{*} \\
0,0252 \\
-0,4296^{*}\end{array}$ \\
\hline $\begin{array}{l}\text { Acém } \\
(\% \mathrm{PCVZ}) \\
\text { "Acém" } \\
(\% E B W) \\
\end{array}$ & $\begin{array}{l}\text { PCVZ }(\mathrm{kg}) \\
\text { COMPCAR }(\mathrm{cm}) \\
\text { EGOR }(\mathrm{mm}) \\
\text { AOL }\left(\mathrm{cm}^{2}\right)\end{array}$ & $\begin{array}{l}0,8330^{* *} \\
0,7089 * \\
0,8125^{* *} \\
0,7758^{* *}\end{array}$ & $\begin{array}{l}0,5401 \\
0,4268 \\
0,5045 \\
0,5219 \\
\end{array}$ & $\begin{array}{l}0,9125 * * \\
0,8304 * * \\
0,4167 \\
0,8142 * *\end{array}$ & $\begin{array}{l}0,5016 \\
0,1688 \\
0,3310 \\
0,4047 \\
\end{array}$ & $\begin{array}{l}0,3940 \\
0,2337 \\
0,2163 \\
0,1347 \\
\end{array}$ & $\begin{array}{l}0,7505 * * \\
0,6009 * * \\
0,5564 * * \\
0,6405 * * \\
\end{array}$ \\
\hline $\begin{array}{l}\text { Ponta agulha } \\
\text { (\%PCVZ) } \\
\text { Spare ribs } \\
(\% E B W) \\
\end{array}$ & $\begin{array}{l}\text { PCVZ }(\mathrm{kg}) \\
\operatorname{COMPCAR}(\mathrm{cm}) \\
\text { EGOR }(\mathrm{mm}) \\
\operatorname{AOL}\left(\mathrm{cm}^{2}\right) \\
\end{array}$ & $\begin{array}{l}-0,1949 \\
-0,2185 \\
-0,0479 \\
-0,1005\end{array}$ & $\begin{array}{l}0,8220 * * \\
0,7922 * * \\
0,5469 \\
0,7334 * *\end{array}$ & $\begin{array}{l}0,8515^{* *} \\
0,8560^{* *} \\
0,6045^{*} \\
0,7100^{*}\end{array}$ & $\begin{array}{l}0,8214^{* *} \\
0,0640 \\
0,4491 \\
0,7813^{* *}\end{array}$ & $\begin{array}{r}0,1962 \\
0,1033 \\
0,0950 \\
-0,5081\end{array}$ & $\begin{array}{l}0,2836 \\
0,2470 \\
0,1850 \\
0,3458 *\end{array}$ \\
\hline $\begin{array}{l}\text { Alcatra } \\
\text { (\%PCVZ) } \\
\text { Whole shoulder } \\
(\% E B W)\end{array}$ & $\begin{array}{l}\operatorname{PCVZ}(\mathrm{kg}) \\
\operatorname{COMPCAR}(\mathrm{cm}) \\
\operatorname{EGOR}(\mathrm{mm}) \\
\operatorname{AOL}\left(\mathrm{cm}^{2}\right)\end{array}$ & $\begin{array}{l}-0,3840 \\
-0,3563 \\
-0,1646 \\
-0,2908\end{array}$ & $\begin{array}{l}0,0099 \\
0,1526 \\
0,2462 \\
0,1519\end{array}$ & $\begin{array}{r}0,0986 \\
0,3754 \\
-0,3011 \\
0,1284\end{array}$ & $\begin{array}{l}0,2300 \\
0,4176 \\
0,2122 \\
0,3925\end{array}$ & $\begin{array}{r}-0,2512 \\
-0,1328 \\
0,2556 \\
-0,4617\end{array}$ & $\begin{array}{r}-0,0552 \\
0,0574 \\
0,0657 \\
0,0097\end{array}$ \\
\hline $\begin{array}{l}\text { Coxão } \\
\text { (\%PCVZ) } \\
\text { Cushion } \\
(\% E B W)\end{array}$ & $\begin{array}{l}\text { PCVZ }(\mathrm{kg}) \\
\text { COMPCAR }(\mathrm{cm}) \\
\text { EGOR }(\mathrm{mm}) \\
\text { AOL }\left(\mathrm{cm}^{2}\right)\end{array}$ & $\begin{array}{l}-0,6469 * \\
-0,3940 \\
-0,7337 * * \\
-0,4363\end{array}$ & $\begin{array}{l}-0,6084 * \\
-0,5076 \\
-0,2812 \\
-0,2774\end{array}$ & $\begin{array}{r}-0,1651 \\
0,3032 \\
-0,2992 \\
-0,2442\end{array}$ & $\begin{array}{l}-0,1164 \\
0,7687 * * \\
-0,1462 \\
-0,2668\end{array}$ & $\begin{array}{r}-0,2548 \\
0,0130 \\
-0,3852 \\
-0,1755\end{array}$ & $\begin{array}{l}-0,4705^{* *} \\
-0,2784 \\
-0,4406^{* *} \\
-0,2769\end{array}$ \\
\hline $\begin{array}{l}\mathrm{MC}^{8} \\
(\% \mathrm{PCVZ}) \\
(\% E B W)\end{array}$ & $\begin{array}{l}\text { PCVZ }(\mathrm{kg})^{4} \\
\text { COMPCAR }(\mathrm{cm})^{5} \\
\text { EGOR }(\mathrm{mm})^{6} \\
\text { AOL }\left(\mathrm{cm}^{2}\right)^{7}\end{array}$ & $\begin{array}{l}-0,1064 \\
-0,0274 \\
-0,0205 \\
-0,1012\end{array}$ & $\begin{array}{r}-0,1326 \\
-0,2146 \\
-0,1126 \\
0,1502\end{array}$ & $\begin{array}{l}0,6494 * \\
0,8304 * * \\
0,4346 \\
0,5570\end{array}$ & $\begin{array}{r}0,1203 \\
-0,2743 \\
0,2984 \\
0,3077\end{array}$ & $\begin{array}{r}0,3669 \\
0,5068 \\
-0,0240 \\
0,4111\end{array}$ & $\begin{array}{c}0,1898 \\
0,2075 \\
-0,0537 \\
0,4035^{*}\end{array}$ \\
\hline $\begin{array}{l}\mathrm{OC}^{9} \\
(\% \mathrm{PCVZ}) \\
(\% E B W)\end{array}$ & $\begin{array}{l}\text { PCVZ }(\mathrm{kg}) \\
\text { COMPCAR }(\mathrm{cm}) \\
\text { EGOR }(\mathrm{mm}) \\
\text { AOL }\left(\mathrm{cm}^{2}\right)\end{array}$ & $\begin{array}{l}-0,3183 \\
-0,1771 \\
-0,5385 \\
-0,4552 \\
\end{array}$ & $\begin{array}{l}-0,5593 \\
-0,5116 \\
-0,6129 * \\
-0,1823\end{array}$ & $\begin{array}{l}-0,6009 \\
-0,4930 \\
-0,0979 \\
-0,5920\end{array}$ & $\begin{array}{l}-0,4472 \\
-0,0999 \\
-0,5207 \\
-0,4755\end{array}$ & $\begin{array}{r}0,1169 \\
0,0665 \\
-0,3694 \\
-0,0314\end{array}$ & $\begin{array}{l}-0,4983^{* *} \\
-0,3919^{*} \\
-0,4609^{* *} \\
-0,3625^{*}\end{array}$ \\
\hline $\begin{array}{l}\text { ADcar }{ }^{10} \\
(\% \mathrm{PCVZ}) \\
(\% E B W)\end{array}$ & $\begin{array}{l}\operatorname{PCVZ}(\mathrm{kg}) \\
\text { COMPCAR }(\mathrm{cm}) \\
\text { EGOR }(\mathrm{mm}) \\
\text { AOL }\left(\mathrm{cm}^{2}\right)\end{array}$ & $\begin{array}{l}0,5849^{*} \\
0,3793 \\
0,6083^{*} \\
0,6158^{*}\end{array}$ & $\begin{array}{l}0,5308 \\
0,5326 \\
0,5450 \\
0,2103\end{array}$ & $\begin{array}{l}0,9282^{* *} \\
0,6898^{*} \\
0,3964 \\
0,9260 * *\end{array}$ & $\begin{array}{r}0,2314 \\
0,5716 \\
0,1230 \\
-0,0283\end{array}$ & $\begin{array}{c}-0,4446 \\
-0,6737 * \\
0,2408 \\
-0,4631\end{array}$ & $\begin{array}{l}0,5166^{* *} \\
0,3665^{*} \\
0,5698^{* *} \\
0,2514\end{array}$ \\
\hline $\begin{array}{l}\text { ADvis } 11 \\
(\% \mathrm{PCVZ}) \\
(\% E B W)\end{array}$ & $\begin{array}{l}\text { PCVZ }(\mathrm{kg}) \\
\text { COMPCAR }(\mathrm{cm}) \\
\text { EGOR }(\mathrm{mm}) \\
\text { AOL }\left(\mathrm{cm}^{2}\right)\end{array}$ & $\begin{array}{l}0,7966^{* *} \\
0,6098^{*} \\
0,8131^{* *} \\
0,6951^{*}\end{array}$ & $\begin{array}{l}0,6806^{*} \\
0,5483 \\
0,5118 \\
0,3777\end{array}$ & $\begin{array}{l}0,8726^{* *} \\
0,7430^{* *} \\
0,5326 \\
0,9558^{* *}\end{array}$ & $\begin{array}{l}0,2115 \\
0,0497 \\
0,0743 \\
0,4358\end{array}$ & $\begin{array}{r}-0,3033 \\
-0,5220 \\
0,3186 \\
0,0291\end{array}$ & $\begin{array}{l}0,7596 * * \\
0,5833 * * \\
0,6512 * * \\
0,5759 * *\end{array}$ \\
\hline $\begin{array}{l}\mathrm{TADC}^{12} \\
(\% \mathrm{PCVZ}) \\
(\% E B W)\end{array}$ & $\begin{array}{l}\text { PCVZ }(\mathrm{kg}) \\
\text { COMPCAR }(\mathrm{cm}) \\
\text { EGOR }(\mathrm{mm}) \\
\text { AOL }\left(\mathrm{cm}^{2}\right)\end{array}$ & $\begin{array}{l}0,6724^{*} \\
0,4634 \\
0,6947^{*} \\
0,6653^{*}\end{array}$ & $\begin{array}{l}0,6005^{*} \\
0,5647 \\
0,5639 \\
0,2684\end{array}$ & $\begin{array}{l}0,9304 * * \\
0,7205^{*} \\
0,4465 \\
0,9544 * *\end{array}$ & $\begin{array}{l}0,2741 \\
0,5721 \\
0,1372 \\
0,0689\end{array}$ & $\begin{array}{l}-0,4849 \\
-0,7473 * * \\
0,2940 \\
-0,4350\end{array}$ & $\begin{array}{l}0,6124 * * \\
0,4461 * * \\
0,6241 * * \\
0,3548 *\end{array}$ \\
\hline
\end{tabular}

\footnotetext{
* Significativo a $5 \%$ (Significant at $5 \%$ ).

** Significativo a $1 \%$ (Significant at $1 \%$ ).

$1 \quad 1 / 2$ Caracu $\times 1 / 2$ Zebu $(1 / 2$ Caracu $\times 1 / 2$ Zebu).

$21 / 2$ Holandês $\times 1 / 2$ Zebu $(1 / 2$ Holstein $\times 1 / 2$ Zebu).

3 Nelore (Nellore).

4 Peso de corpo vazio (Empty body weight).

5 Comprimento de carcaça (Carcass length).

6 Espessura de gordura (Fat thickness).

7 Área de olho de lombo (Loin eye área).

8 Tecido muscular da carcaça (Carcass muscle tissue).

9 Tecido ósseo da carcaça (Carcass bone tissue).

10 Tecido adiposo da carcaça (Carcass fat tissue).

11 Tecido adiposo visceral (Visceral fat tissue).

12 Total de tecido adiposo corporal (Total of body fat tissue).
}

\section{R. Bras. Zootec., v.33, n.6, p.1581-1590, 2004}


vadas quando se analisam dados das duas categorias em conjunto. $\mathrm{O}$ tamanho relativo do $\mathrm{COX}$ apresenta correlações negativas significativas com o PCVZ e a EGOR, indicando que a porcentagem de COX no corpo animal é reduzida, à medida que o animal cresce e atinge a maturidade. Em geral, estes resultados indicam tendência geral de maior participação dos cortes de menor valor comercial (cortes do dianteiro) em animais de maior peso corporal e/ou maior estádio de maturidade da carcaça (indicado pela EGOR).

Nenhum dos componentes físicos da carcaça (MC, ADcar ou OC) apresentou alta correlação entre seu tamanho relativo e as características mensuráveis do corpo animal. Isto indica haver pequenas variações aleatórias nos conteúdos relativos destes tecidos ou variações que não são prémensuráveis a partir do grupo genético, da categoria e das características avaliadas. Peron (1991) e Jorge et al. (1997a) também encontraram baixos coeficientes de correlação entre os tecidos constituintes da carcaça e as características corporais mensuráveis. Esses autores destacam as correlações negativas entre o tamanho corporal (PCVZ) e os tecidos ósseo e muscular, indicativas da alometria negativa destes tecidos, também observadas nesta pesquisa (com exceção dos animais Nelore). Esta correlação positiva do tecido muscular com o crescimento animal, observada no grupo genético Nelore, pode ser explicada por ganho compensatório destes animais. Segundo o modelo de Berg \& Butterfield (1976), caso estes animais tenham sofrido um período de restrição alimentar anterior ao experimento, os mesmos tentariam restabelecer o conteúdo corporal de músculos original para seu peso (provocando crescimento muscular acelerado, durante o período experimental, e as correlações positivas observadas nesta pesquisa).

O tamanho relativo do ADvis e do TADC são bem correlacionados com várias das características mensuráveis do corpo animal (em especial o PCVZ). As correlações positivas e significativas encontradas entre os tamanhos relativos destes tecidos adiposos e o PCVZ e a EGOR indicam que o tamanho relativo dos tecidos adiposos corporais tende a aumentar com o avançar do crescimento e da maturidade dos animais, sendo possível estimar os tamanhos relativos a partir destas duas características.

\section{Conclusões}

Animais provenientes de seleção para corte na terminação apresentaram rendimentos de carcaça $7 \%$ maiores que aqueles de origem leiteira.

Grupos genéticos provenientes de raças com aptidão leiteira mostraram tamanhos relativos de órgãos $9 \%$ maior (21\% menos tecido adiposo na carcaça), bem como maior participação da gordura interna no total de tecido adiposo corporal.

Em virtude das baixas correlações encontradas, não é confiável estimar os tamanhos relativos dos componentes corporais estudados a partir das características corporais mensuráveis analisadas.

\section{Literatura Citada}

BERG, R.T.; BUTTERFIELD, R.M. New concepts of cattle growth. Sidney: Sidney University Press, 1976. 240p.

CASTillo ESTRAdA, L.H. Composição corporal e exigências de proteína, energia e macroelementos minerais (Ca, P, Mg, Na e K), características da carcaça e desempenho do Nelore e mestiços em confinamento. Viçosa, MG: Universidade Federal de Viçosa, 1996. 129p. Tese (Doutorado em Zootecnia) - Universidade Federal de Viçosa, 1996.

FERREL, C.L.; JENKINS, T.G. Body composition and energy utilization by steers of diverse genotypes fed a highconcentrate diet during the finishing period I: Angus, Belgian Blue, Hereford, and Piemontese sires. Journal of Animal Science, v.76, p.637-646, 1998a.

FERREL, C.L.; JENKINS, T.G. Body composition and energy utilization by steers of diverse genotypes fed a highconcentrate diet during the finishing period I: Angus, Boran, Brahman, Hereford and Tuli sires. Journal of Animal Science, v.76, p.647-657, 1998b.

FREITAS, J.A. Composição corporal e exigência de energia e proteína de bovinos (zebuínos e mestiços) e bubalinos não-castrados, em confinamento. Viçosa, MG: Universidade Federal de Viçosa, 1995. 75p. Dissertação (Mestrado em Zootecnia) - Universidade Federal de Viçosa, 1995.

GALVÃO, J.G.; FONTES, C.A.A.; PIRES, C.C. et al. Características e composição física da carcaça de bovinos não-castrados, abatidos em três estágios de maturidade (estudo II) de três grupos raciais. Revista Brasileira de Zootecnia, v.20, n.5, p.502-512, 1991.

GESUALDI JR., A.; PAULINO, M.F.; VALADARES FILHO, S.C. et al. Níveis de concentrado na dieta de novilhos F1 Limousin x Nelore: características de carcaça. Revista Brasileira de Zootecnia, v.29, n.5, p.1467-1473, 2000.

GUIMARÃES, R.F. Ganho de peso, consumo e conversão alimentar, composição corporal e características de carcaça de novilhos mestiços durante o ganho compensatório. Viçosa, MG: Universidade Federal de Viçosa, 1999. 111p. Dissertação (Mestrado em Zootecnia) Universidade Federal de Viçosa, 1999. 
HANKINS, O.G.; HOWE, P.E. Estimation of the composition of' beef carcasses and cuts. Washington. D.C. (Tech. Bulletin - USDA, 926). 1946.

JORGE, A.M.; FONTES, C.A.A.; SOARES, J.E. et al. Características quantitativas da carcaça de bovinos e bubalinos, abatidos em diferentes estádios de maturidade. Revista Brasileira de Zootecnia, v.26, n.5, p.1039-1047, 1997a.

JORGE, A.M.; FONTES, C.A.A.; FREITAS, J.A et al. Rendimento da carcaça e de cortes básicos de bovinos e bubalinos, abatidos em diferentes estádios de maturidade. Revista Brasileira de Zootecnia, v.26, n.5, p.1048-1054, 1997b.

JORGE, A.M.; FONTES, C.A.A.; PAULINO, M.F. et al. Tamanho relativo dos órgãos internos de zebuínos sob alimentação restrita e ad libitum. Revista Brasileira de Zootecnia, v.28, n.2, p.374-380, 1999a.

JORGE, A.M.; FONTES, C.A.A.; PAULINO, M.F. et al. Desempenho produtivo de animais de quatro raças zebuínas, abatidos em três estádios de maturidade. 2. Características da carcaça. Revista Brasileira de Zootecnia, v.28, n.2, p.381-387, 1999b.

LANA, R.P. Sistema Viçosa de formulação de rações. Viçosa, MG: Universidade Federal de Viçosa, 2000. 60p.

NATIONAL RESEARCH COUNCIL - NRC. Nutrient requirements of beef cattle. 7.ed. Washington, D.C.: 1996. 242p.

OLIVEIRA, R.C. Ganho de peso, características de carcaça e composição corporal de novilhos em regime de pastejo em capim-elefante durante a estação chuvosa. Viçosa, MG: Universidade Federal de Viçosa, 1999. 109p. Dissertação (Mestrado em Zootecnia) - Universidade Federal de Viçosa, 1999.

OLIVEIRA, S.R. Desempenho e características da carcaça de novilhos Nelores não-castrados. Viçosa, MG: Universidade Federal de Viçosa, 1998. 58p. Dissertação (Mestrado em Zootecnia) - Universidade Federal de Viçosa, 1998.

OWENS, F.N.; GILL, D.R.; SECRIST, D.S. Review of some aspects of growth and development of feedlot cattle. Journal of Animal Science, v.73, p.3152-3172, 1995.

PAULINO, M.F.; FONTES, C.A.A.; JORGE, A.M. et al. Composição corporal e exigências de energia e proteína para ganho de peso de bovinos de quatro raças zebuínas. Revista Brasileira de Zootecnia, v.28, n.3, p.627-633, 1999.

PERON, A.J.; FONTES, C.A.A.; LANA, R.P. et al. Rendimento de carcaça e de seus cortes básicos e área corporal de bovinos de cinco grupos genéticos, submetidos à alimentação restrita e ad libitum. Revista Brasileira de Zootecnia, v.22, n.1, p.238-247, 1993a.
PERON, A.J.; FONTES, C.A.A.; LANA, R.P. et al. Tamanho de órgãos internos e distribuição da gordura corporal em novilhos de cinco grupos genéticos, submetidos à alimentação restrita e ad libitum. Revista Brasileira de Zootecnia, v.22, n.5, p.813-819, 1993 b.

PERON, A.J. Características e composição física e química corporal e da carcaça de bovinos de cinco grupos genéticos, submetidos à alimentação restrita e ad libitum. Viçosa, MG: Universidade Federal de Viçosa, 1991. 126p. Dissertação (Mestrado em Zootecnia) - Universidade Federal de Viçosa, 1991.

STATISTICAL ANALYSES SYSTEM - SAS. SAS/STAT User's Guide. Version 6. 4.ed. Cary: 1989. 943p.

SIGNORETTI, R.D.; SILVA, J.F.C.; VALADARES FILHO, S.C. et al. Composição corporal e exigências líquidas de energia e proteína de bezerros da raça Holandesa alimentados com dietas contendo diferentes níveis de volumoso. Revista Brasileira de Zootecnia, v.28, n.1, p.195-204, 1999a.

SIGNORETTI, R.D.; ARAÚJO, G.G.L.; SILVA, J.F.C. et al. Características quantitativas das partes do corpo não integrantes da carcaça animal e desenvolvimento do trato gastrintestinal de bezerros da raça Holandesa alimentados com dietas contendo quatro níveis de concentrado. Revista Brasileira de Zootecnia, v.28, n.4, p.875-882, 1999b.

VÉRAS, A.S.C.; VALADARES FILHO, S.C.; SILVA, J.F.C. et al. Efeito do nível de concentrado sobre o peso dos órgãos internos e do conteúdo gastrintestinal de bovinos Nelore nãocastrados. Revista Brasileira de Zootecnia, v.30, n.3, p.1120-1126, 2001a (Suplemento 1).

VÉRAS, A.S.C.; VALADARES FILHO, S.C.; SILVA, J.F.C. et al. Predição da composição corporal e dos requisitos de energia e proteína para ganho de peso de bovinos, não-castrados, alimentados com rações contendo diferentes níveis de concentrado. Revista Brasileira de Zootecnia, v.30, n.3, p.1127-1134, 2001b (Suplemento 1).

ZERVOUDAKIS, J.T.; PAULINO, M.F.; DETMANN, E. Et al. Desempenho, características de carcaça e exigências líquidas de proteína e energia de bovinos suplementados no período das águas. Revista Brasileira de Zootecnia, v.30, n.4, p.1381-1389, 2001. 